\title{
PENCEGAHAN TERJADINYA COMPUTER VISION SYNDROME (CVS) AKIBAT PEMBELAJARAN DARING DI MASA PANDEMI COVID-19 PADA SISWA MTSN 1 LUMAJANG
}

https://doi.org/10.33024/jkpm.v4i6.4333

\author{
Indriana Noor Istiqomah ${ }^{*}$, Laili Nur Azizah², Mashuri ${ }^{3}$ \\ 1-3Prodi D3 Keperawatan Fakultas Keperawatan Universitas Jember \\ Disubmit: 07 Mei 2021 Diterima: 10 Juni 2021 Diterbitkan: 01 Desember 2021
}

Email Korespondensi: indrinoor@gmail.com

\begin{abstract}
ABSTRAK
Computer Vision Syndrome (CVS) merupakan kumpulan gejala yang muncul akibat penggunaan laptop atau komputer. Penggunaan laptop atau menatap layar laptop lebih dari 2 jam dan tidak diselingi dengan mengistirahatkan mata selama 15 menit, dapat menimbulkan gejala CVS. Adanya pembelajaran daring di Indonesia, dan diberlakukannya pembatasan sosial saat pandemi Covid-19 sejak bulan Maret 2020, menyebabkan seluruh fasilitas pendidikan menghentikan mengalihkan sistem pembelajaran tatap muka menjadi sistem pembelajaran dalam jaringan (daring). Pembelajaran daring yang biasanya dilakukan selama 46 jam dalam sehari (tidak termasuk pebugasan di luar jam sekolah), tentu dapat memberikan dampak buruk bagi kesehatan mata siswa. Tujuan kegiatan ini adalah meningkatkan pemahaman siswa tentang cara pencegahan CVS sehingga dapat membantu siswa untuk berperan aktif dalam upaya pencegahan terjadinya CVS. Metode kegiatan pengabdian ini yang digunakan dalam kegiatan ini adalah memberikan penyuluhan melalui ruang Zoom tentang pencegahan CVS menggunakan media power point yang dilengkapi gambar-gambar dan juga video roleplay mengatasi CVS secara mandiri, serta pemberian leaflet tentang pencegahan CVS. Hasil dari kegiatan ini adalah pengetahuan siswa tentang pencegahan CVS meningkat.
\end{abstract}

Kata kunci: computer vision syndrom, pembelajaran daring.

\section{ABSTRACT}

Computer Vision Syndrome (CVS) is a collection of symptoms that arise from using a laptop or computer. Using a computer or staring at a laptop screen for more than 2 hours and not resting your eyes for 15 minutes can cause CVS symptoms. The existence of online learning in Indonesia, and the imposition of social restrictions during the Covid-19 pandemic since March 2020, have caused all educational facilities to stop turning face-to-face learning systems into online learning systems. Online learning, which is usually carried out for 4-6 hours a day (excluding work outside school hours), can undoubtedly harm students' eye health. This activity aims to increase students' understanding of how to prevent CVS so that it can help students take an active role in preventing CVS. This activity's method is to provide counseling through the Zoom room about CVS prevention using PowerPoint media equipped with pictures and video 
roleplay to overcome CVS independently and give leaflets on CVS prevention. The result of this activity was that the knowledge of MTsN 1 Lumajang students about CVS prevention increased.

Keywords: computer vision syndrome, online learning

\section{PENDAHULUAN}

Komputer merupakan alat yang sangat berperan dalam berbagai bidang seperti perbankan, bisnis dan perdagangan, perkantoran, jasa, pengawasan, hiburan, bahkan pendidikan/pembelajaran seperti saat pandemi ini. Pemanfaatan teknologi komputer dalam pendidikan dan pembelajaran bertujuan menigkatkan kualitas dan inovasi pendidikan, tetapi sayangnya, penggunaan komputer dalam durasi dan jangka waktu lama akan menimbulkan berbagai masalah kesehatan (Sari, F.T.A., Himayani, R., 2018).

Baru-baru ini perkiraan penggunaan internet berkisar dari 77,4\% dari populasi Amerika Utara untuk 10,9\% dari Afrika, dengan perkiraan 1966514 816 pengguna di seluruh dunia (atau $28,7 \%$ dari populasi dunia)( Rosenfield M. , 2011). Menurut penelitian, lebih dari 143 juta orang bekerja menggunakan komputer setiap harinya, $90 \%$ diantaranya menderita kelelahan mata. Sekitar 70\% pekerja komputer di seluruh dunia dilaporkan memiliki masalah penglihatan dan terjadi peningkatan insidensi. Hampir $90 \%$ anak-anak di Amerika Serikat menggunakan komputer di rumah atau di sekolah setiap hari. Durasi pemakaian komputer yang terlalu lama ini akan menimbulkan berbagai masalah, salah satunya adalah Computer Vision Syndrome (CVS) (Rahman ZA, Sanip S., 2011 dalam Sari FTA, 2018).

Computer Vision Syndrome (CVS) merupakan kumpulan gejala yang muncul akibat penggunaan laptop atau komputer. Durasi penggunaan laptop menjadi salah satu faktor resiko yang dapat menimbulkan CVS (Hidayati, R.M., Bayhakki, \& Woferst, R., 2017). Penggunaan laptop atau menatap layar laptop lebih dari 2 jam dan tidak diselingi dengan mengistirahatkan mata selama 15 menit, dapat menimbulkan gejala CVS (NIOSH, 2008 dalam Hidayati, R.M., Bayhakki, \& Woferst, R., 2017). American Optometric Association (AOA) mendefinisikan sindroma penglihatan pada pemakaian komputer (CVS) sebagai masalah mata majemuk yang berkaitan dengan pekerjaan jarak dekat yang dialami seseorang selama menggunakan atau berhubungan dengan penggunaan komputer, seperti mata tegang, sakit kepala, mata kabur (untuk penglihatan dekat dan/atau jauh), mata kering dan mengalami iritasi, penurunan kemampuan memfokuskan mata, sakit pada leher, sakit pada area punggung, dan peka terhadap cahaya (AOA, 2011 dalam Hidayati, R.M., Bayhakki, \& Woferst, R., 2017).

Apabila gejala-gejala ini diabaikan, bisa mengarah kepada gangguan mata yang serius. Dari penelitian di Jepang meyimpulkan bahwa CVS bisa menjadi Glaukoma (kerusakan syaraf optic mata) yang dapat berujung kepada kebutaan (Tatemichi, M., et al, 2004).

Adanya pembelajaran daring di Indonesia diberlakukannya pembatasan sosial saat pandemi Covid-19 sejak bulan Maret 2020, menyebabkan seluruh fasilitas pendidikan menghentikan mengalihkan sistem pembelajaran tatap muka menjadi sistem pembelajaran dalam jaringan (daring). Pembelajaran daring biasanya dilakukan selama 4-6 jam dalam sehari (tidak termasuk pebugasan di luar jam sekolah), tentu memberikan dampak buruk bagi kesehatan mata siswa. 
Salah satu bentuk pencegahan adalah dengan memberikan meningkatkan pengetahuan melalui penyuluhan pencegahan terjadinya computer vision syndrome yang dapat dilakukan dengan pemberian edukasi melalui ruang zoom, video edukasi dan pemberian leaflet. Hal ini mengingat berakhirnya masa pandemi Covid-19 yang tidak bisa diprediksi sehingga pembelajaran daring diperkirakan akan mengalami perpanjangan waktu. Untuk itulah perlunya edukasi pada siswa MTsN 1 Lumajang agar membantu madrasah khususnya siswa untuk meningkatkan pemahaman tentang penggunaan komputer secara benar agar terhindar dari gangguan penglihatan.

\section{MASALAH}

Madrasah Tsanawiyah Negeri 1 Lumajang (MTsN 1 Lumajang) merupakan madrasah, setaraf sekolah menengah pertama di Lumajang, yang merupakan satu-satunya madrasah negeri yang telah menerapkan pembelajaran daring sejak pertengahan Maret 2020 sampai dengan saat ini. Pembelajaran daring dimulai pada hari Senin sampai Sabtu pukul 08.00-11.00 setiap harinya. Sebagian besar siswa menggunakan laptop sebagai alat bantu selama pembelajaran daring. Laptop mempunyai sisi ergonomis dengan desain atau bentuk yang cukup efisien dan nyaman bagi pengguna. Efisiensi dan kenyamanan ini juga berpengaruh terhadap lamanya penggunaan laptop. Apalagi masa anak dan remaja masih menggemari komputer/laptop sebagai media bermain/hiburan. Apabila siswa ini tidak diberikan edukasi tentang gangguan penglihatan akibat penggunaan komputer, maka berpotensi terjadinya gangguan mata.

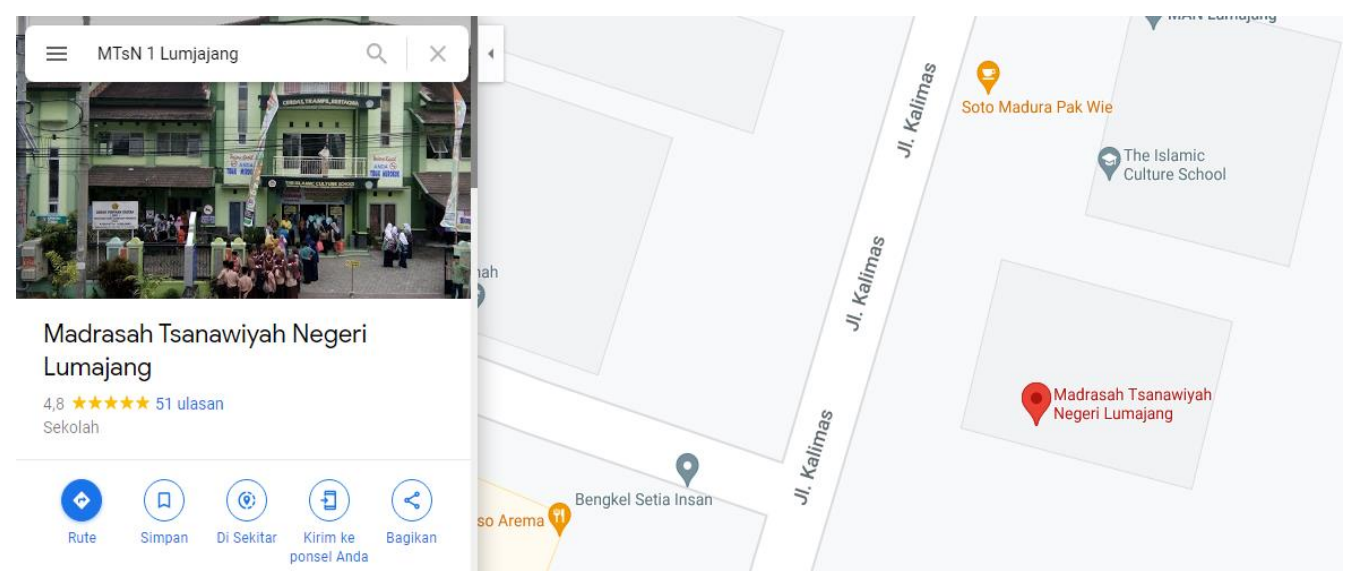

Gambar 2.1 Peta Lokasi Kegiatan

\section{METODE}

a. Tahap Persiapan

Tahap persiapan meliputi koordinasi dengan pihak MTsN 1 Lumajang tentang jadwal penyuluhan, kemudian penyusunan materi dan pembuatan video roleplay mengatasi CVS secara mandiri oleh tim, serta persiapan pelaksanaan penyuluhan meliputi ruang zoom yang digunakan, pembagian tugas baik dari tim pengabdian masyarakat maupun dari pihak MTsN 1 Lumajang. 
b. Tahap Pelaksanaan

Kegiatan ini berlangsung pada hari minggu, 20 September 2020, jam 08.30-10.30 WIB. Link sudah disebarkan melalui wali kelas masing-masing sejak 3 hari sebelum pelaksanaan. Kegiatan dilaksanakan secara daring melalui zoom yang diikuti oleh siswa-siswi MTsN 1 Lumajang yang berjumlah sebanyak 94 orang dan di hadiri serta dibuka oleh Kepala MTsN 1 Lumajang. Selama kegiatan berlangsung, para peserta terlihat sangat antusias mengikuti kegiatan tersebut karena materi yang disajikan disusun dengan sangat menarik menggunakan media power point yang dilengkapi gambar-gambar dan juga video roleplay mengatasi CVS secara mandiri.

c. Evaluasi

1) Struktur

Kegiatan pengabdian ini mendapat sambutan hangat dari siswa-siswi MTsN 1 Lumajang yang dibuktikan dengan umpan balik dari siswa-siswi MTsN 1 Lumajang yang sangat antusias dan bersemangat untuk mengajukan pertanyaan serta sebanyak 94 peserta hadir mengikuti kegiatan pengabdian tersebut dari awal hingga akhir.

2) Proses

Kegiatan berlangsung selama 120 menit yang terbagi dalam 30 menit pertama perkenalan, pembukaan dan sambutan, 45 menit penyampaian materi tentang pencegahan Computer Vision Syndrome (CVS) dan pemutaran video roleplay, 30 menit tanya jawab.

\section{HASIL DAN PEMBAHASAN}

Kegiatan ini berlangsung selama 120 menit yang terbagi dalam 30 menit pertama perkenalan, pembukaan dan sambutan, 45 menit penyampaian materi tentang pencegahan Computer Vision Syndrome (CVS) dan pemutaran video roleplay, 30 menit tanya jawab untuk mengevaluasi pengetahuan dan kemampuan siswa-siswi dalam melakukan pencegahan terjadinya CVS. dilaksanakan secara daring melalui zoom yang diikuti oleh siswa-siswi MTsN 1 Lumajang yang berjumlah sebanyak 94 orang dan di hadiri serta dibuka oleh Kepala MTsN 1 Lumajang. Selama kegiatan berlangsung, para peserta terlihat sangat antusias mengikuti kegiatan tersebut karena materi yang disajikan disusun dengan sangat menarik menggunakan media power point yang dilengkapi gambar-gambar dan juga video roleplay mengatasi CVS secara mandiri.

Media Zoom sengaja dipilih dalam penyampaian materi tentang Pencegahan Computerized Vision Syndrom (CVS), karena pembelajaran masih dilaksanakan secara daring. Kegiatan pengabdian ini yang diikuti oleh siswasiswi MTsN 1 Lumajang serta guru dan mahasiswa Prodi D3 Keperawatan Unej. Metode yang digunakan dalam kegiatan ini adalah memberikan penyuluhan tentang Pencegahan Computer vision Syndrom (CVS) menggunakan media power point yang dilengkapi gambar-gambar dan juga video roleplay mengatasi CVS secara mandiri, serta pemberian leaflet tentang pencegahan Computer Vision Syndrome (CVS), serta pemberian leaflet tentang pencegahan Computer Vision Syndrome (CVS).

Beberapa faktor yang menunjang atas keberhasilan kegiatan pengabdian masyarakat ini adalah koordinasi antara tim pengmas dan pihak sekolah, media penyampaian materi yang menarik, serta adanya umpan balik pemateri dan peserta. Sedangkan ada faktor yang menjadi penghambat kegiatan ini 
antara lain adanya keterbatasan waktu serta kondisi teknis seperti sinyal yang kurang stabil menyebabkan peserta keluar masuk ruang zoom.

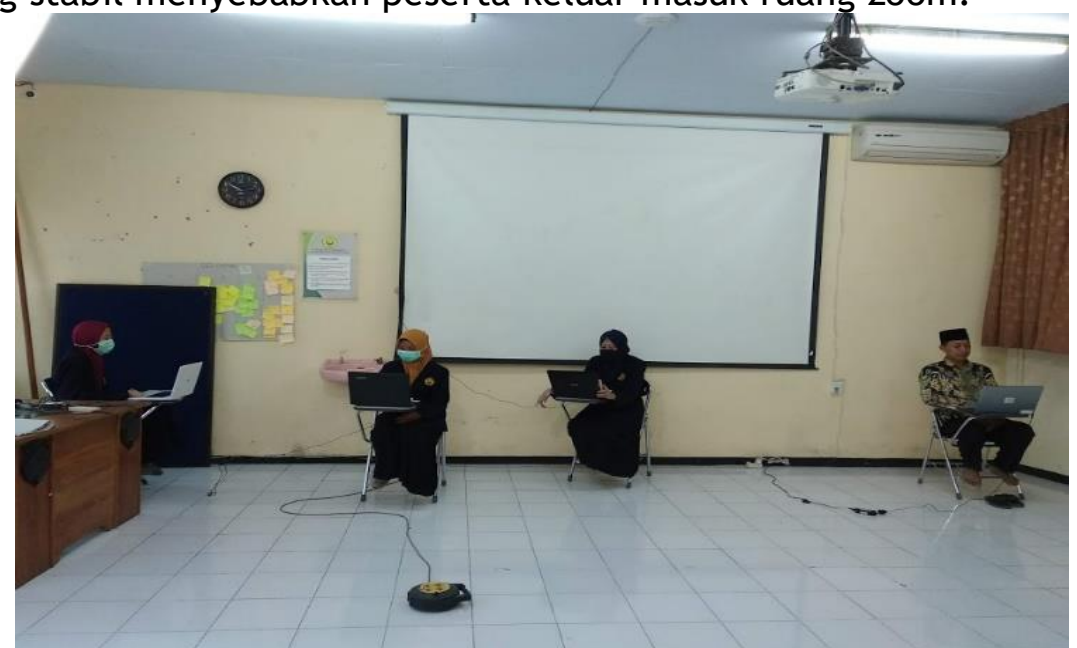

Gambar 1. Tim Pengmas Melakukan Penyuluhan Dari Ruang Zoom

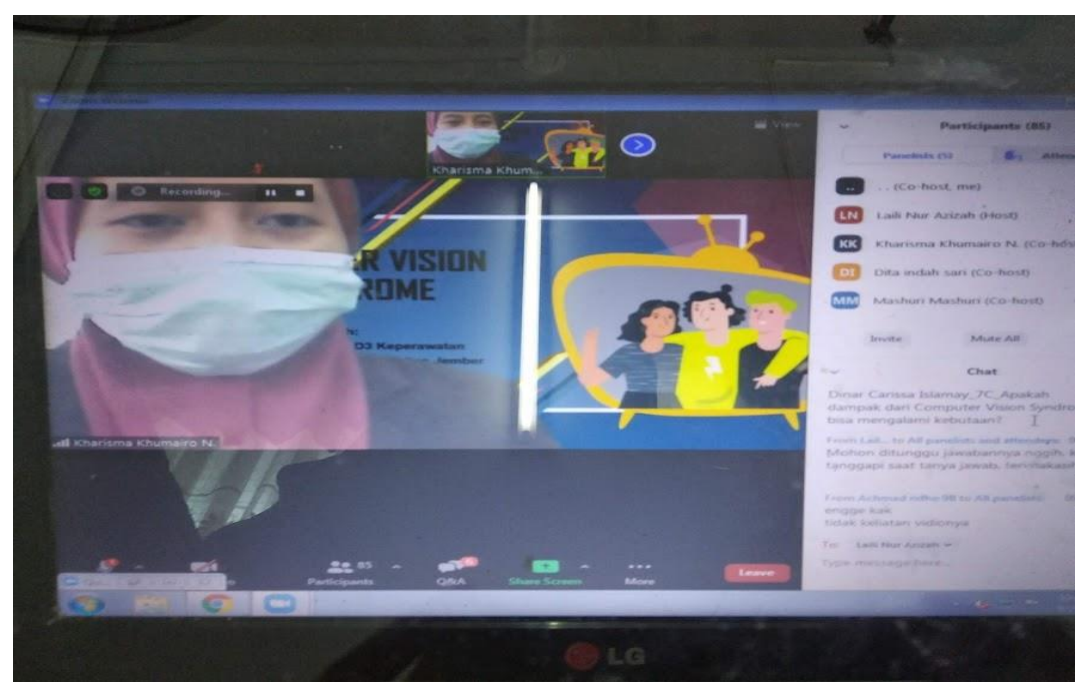

Gambar 2. Penyuluhan Melalui Zoom

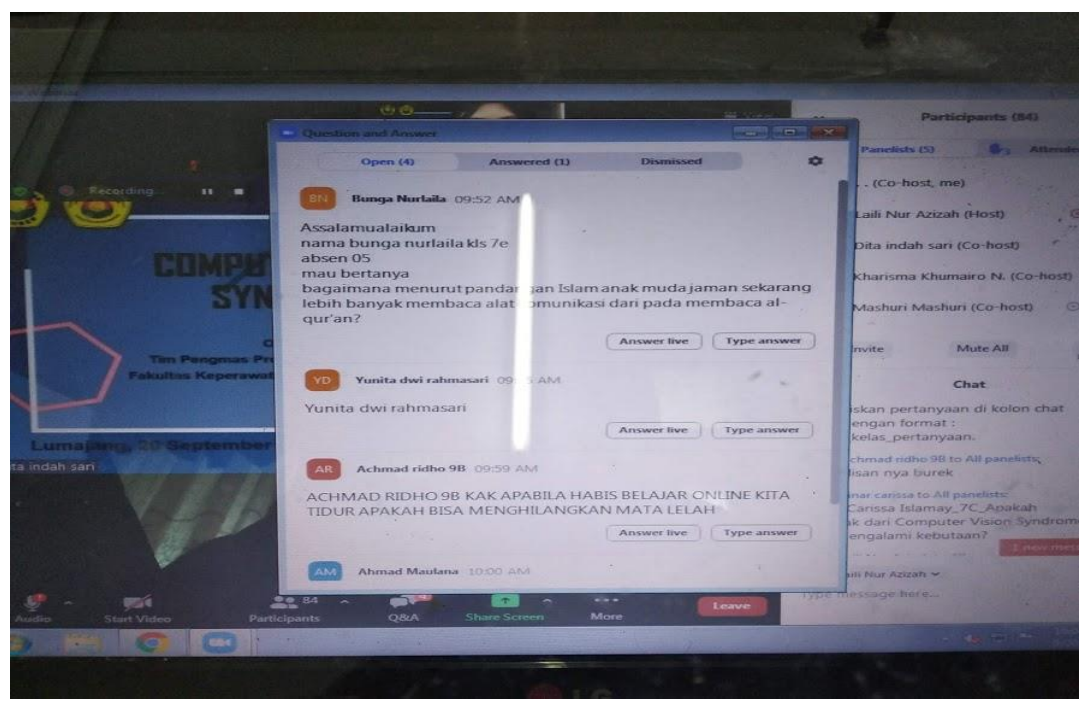




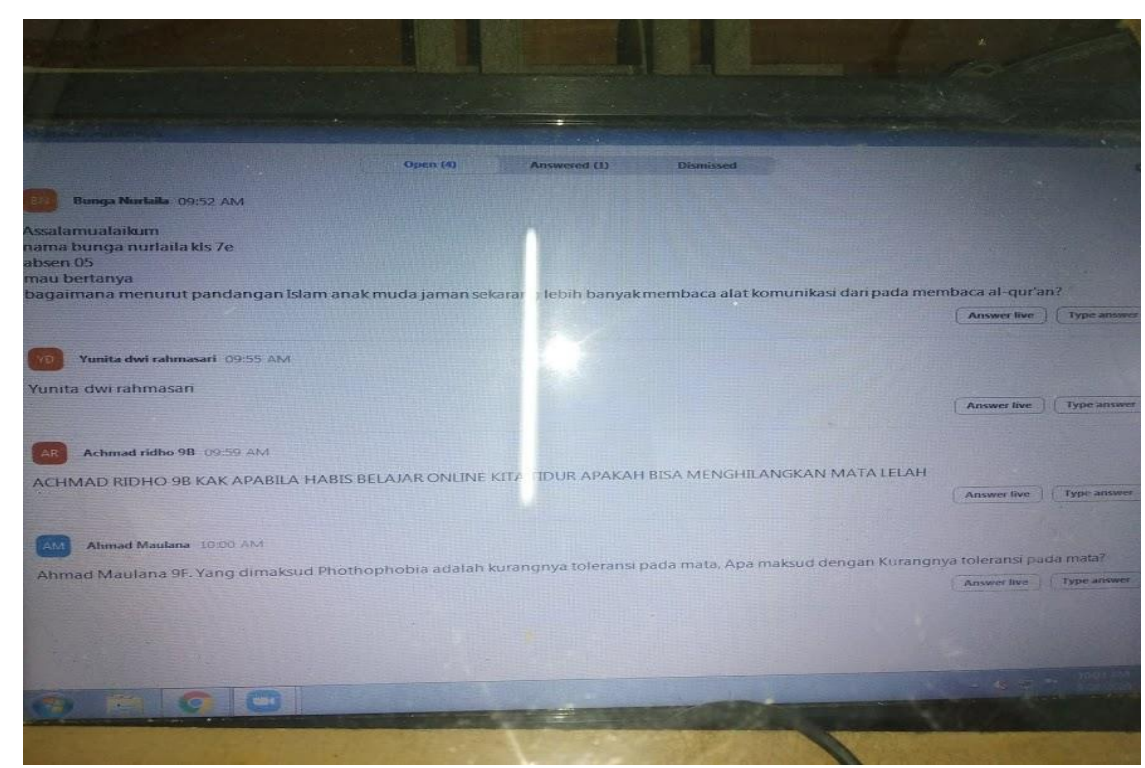

Gambar 3. Daftar chat pertanyaan dari peserta penyuluhan

\section{KESIMPULAN}

Dalam upaya menurunkan angka kejadian Computer Vision Syndrome (CVS) maka dapat dilakukan dengan cara pecegahan primer melalui penyampaian informasi atau pendidikan kesehatan tentang Pencegahan Computer Vision Syndrome (CVS) khususnya pada siswa dan siswi yang melakukan pembelajaran dari rumah melalui daring selama pandemi COVID 19. Salah satunya melalui penyuluhan yang dilakukan pada siswa MTsN 1 Lumajang. Kegiatan ini dihadiri oleh siswa MTsN 1 Lumajang sebanyak 94 orang. Kegiatan ini dapat berlangsung secara tertib dan baik tanpa mengalami hambatan berarti.

Saran dari hasil pengabdian masyarakat ini adalah perlunya mengulangulang edukasi ini melalui video. Untuk video edukasi penanganan dan pencegahan Computer Vision Syndrome CVS bisa di upluoad di Youtube atau Google drive, lalu link video di share ke siswa agar bisa ditonton kembali. Sebagai harapan video edukasi penanganan dan pencegahan CVS dapat diterapkan di rumah. Melalui penyuluhan pencegahan Computer Vision Syndrome (CVS) akibat pembelajaran daring pada siswa MTsN 1 Lumajang ini dapat dijadikan sarana untuk meningkatkan pengetahuan tentang penyakit CVS, sehingga kejadiannya tersebut dapat dicegah.

\section{DAFTAR PUSTAKA}

Akinbinu, T.R., \& Mashalla, Y.J. (2013). Knowledge of computer vision syndrome among computer users in the workplace in Abuja, Nigeria. $J$ Physiol Pathophysiol, 4(4), 58-63.

Hidayati, R.M., Bayhakki, \& Woferst, R. (2017). Hubungan Durasi Penggunaan Laptop Dengan keluhan Computer Vision Syndrome Pada Mahasiswa PSIK UR, Jurnal Ners Indonesia, 8(1), 33-41. https://jni.ejournal.unri.ac.id/ index.php/JNI/article/view/6912 
Nadhira, A.M. (2019). Penyebab Computer Vision Syndrome dan cara mencegahnya. Alodokter. https://www.alodokter.com/penyebabcomputer-vision-syndrome-dan-cara-mencegahnya

Rosenfield, M. (2011). Computer vision syndrome: a review of ocular causes and potential treatments. Ophthalmic Physiol Optics, 31(5), 502-515. https: / / doi.org/10.1111/j.1475-1313.2011.00834.x

Sari, F.T.A., dan Himayani, R. (2018). Faktor Risiko Terjadinya Computer Vision Syndrome. Medical Journal of lampung University, 7(2), 278-282. https://juke.kedokteran.unila.ac.id/index.php/majority/ article/view/1890

Shantakumari, N., Eldeeb, R., Sreedharan, J., \& Gopal, K. (2014). Computer use and vision related problems among university students in Ajman, United Arab Emirate. Ann Med Heal Sci Res, 4(2):258-263

Tatemichi, M., Nakano, T., Tanaka, K., Hayashi, T., Nawa, T., Miyamoto, T., Hiro, H., \& Sugita, M. (2004). Possible association between heavy computer users and glaucomatous visual field abnormalities: a cross sectional study in Japanese workers. J Epidemiol Community Health, 58(12): 1021-7. https://doi.org/10.1136/jech.2003.018127.

Wijaya, C. (2020). 11 Tips Sederhana Mengatasi Computer Vision Syndrome (CVS). Deherba.com. https://www.deherba.com/11-tips-sederhanamengatasi-computer-vision-syndrome-cvs.html

Wijayanti, E. (2018). 5 Bahan Dapur untuk Atasi Mata Lelah. Liputan 6. https: / / www.liputan6.com/health/read/3581976/5-bahan-dapuruntuk-atasi-mata-lelah 